\title{
INHIBITION OF PREMATURE POLYMERIZATION OF CATIONICALLY CURABLE SYSTEMS BY TRIETHANOLAMINE
}

\author{
Jan Vališ (iD, Bohumil Jašúrek (D), Zuzana Brůnová \\ University of Pardubice, Faculty of Chemical Technology, \\ Department of Graphic Arts and Photophysics, Pardubice, Czech Republic
}

\begin{abstract}
This work concerns the inhibition of early polymerization of cationically polymerizable systems. Tested formulations contain 3,4-epoxycyclohexylmethyl-3,4-epoxycyclohexane carboxylate as a reactive monomer, triethanolamine as a stabilizer, and a photoinitiator. Three types of initiators were used: sulphonium salt (tris\{4-[(4-acetylphenyl)sulfanyl]phenyl\}sulfonium hexafluorophosphate), iodonium salt (iodonium (4-methyl-phenyl) [4-(2-ethylpropyl) phenyl] hexafluoro-phosphate)) and iron-arene salt $\left(\eta^{5}\right.$-2,4-cyclopentadien-1-yl) [(1,2,3,4,5,6- $\left.\eta\right)$-(1-methylethyl)benzene]-iron hexafluorophosphate). Prepared formulations were periodically exposed at an increased temperature $\left(60^{\circ} \mathrm{C}\right)$. The long-term stability was tested by viscosity measurement. Viscosity change reflects changes in the distribution of molecular weights in the system or structural changes caused by premature polymerization. The flow behaviour was measured using rheometer Haake RotoVisco 1. The reactivity of the mixtures was tested by FTIR spectroscopy using Nicolet Avatar 320.
\end{abstract}

Key words: cationic polymerization; inhibition; premature polymerization

\section{INTRODUCTION}

UV curable inks are mixtures of reactive components, photoinitiators and other additives. Apart from the rapid photo induced polymerization, these systems undergo the very slow, thermally induced polymerization, which leads to complete gelation. The rate of premature polymerization is influenced by storage temperature, reactivity of the components and thermal stability of the photoinitiators. The premature polymerization is undesirable, because viscosity affects strongly the print quality and a significant increase in viscosity may lead to an irreversible failure of the printing (mainly inkjet) system. Due to the key requirement for ink viscosity stability during storage in the dark and during the printing process, additives inhibiting premature polymerization are put into the ink formulation.

For cationically polymerized inks the amines are added as inhibitors (Takabayashi et al, 2006; Kondo, 2007). These substances react preferentially with the active species initiating the polymerization. They are added in small amounts (e.g. 0.01-0.1 wt. \%) of the ink formulation. After UV exposition, all polymerization inhibitors are depleted by excessive generation of the reactive components (cations) and, sequentially, polymerization initiation and propagation take place.

In the case of cationic polymerization the reactive cations have a much longer lifetime (compared to radicals). Therefore even a small amount of cations prematurely generated in the dark promotes long-lasting polymerization, resulting in slow gelation of the formulation. One of the ways, how to suppress premature polymerization, is cation scavenging by the addition of some nucleofilic substance, e.g. amines (Crivello et al, 1998).

Some cationic photoinitiators (for example the diaryliodonium salts) can be decomposed not only by direct photo-decomposition after UV exposition, but also by redox reactions with suitable free radicals in the dark (Crivello et al, 1998; Yagci et al, 1998). If the premature decomposition of the cationic photoinitiator is supported by premature generation of such free radicals, radical scavengers as quinones or phenolic antioxidants should be effective as the inhibitors of premature polymerization. The use of antioxidants for the inhibition of premature polymerization of cationically polymerizable systems can be found in literature, e.g. (Toagosei America Inc., 2011; Rinker, 2010).

\section{METHODS}

Testing deals with the inhibition effect of triethanolamine (Figure 1a) on premature polymerization of systems consisting of epoxide monomer (Figure 1b) and various types of cationic initiators: iodonium (Figure 1c), sulfonium (Figure 1d), and iron-arene salts (Figure 1e). 


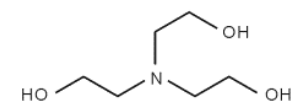

a)

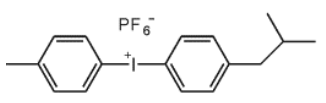

c)

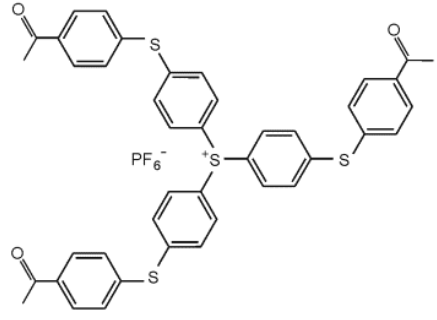

d)

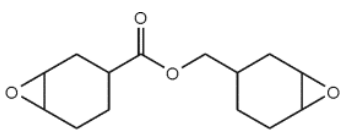

b)

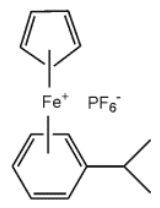

e)

Figure 1: Used materials - (a) triethanolamine, b) 3,4-epoxycyclohexylmethyl-3,4-epoxycyclohexane carboxylate,

c) iodonium (4-methyl-phenyl) [4-(2-ethylpropyl) phenyl] hexafluoro-phosphate, d) tris\{4-[(4-acetylphenyl)sulfanyl]phenyl\}sulfonium hexafluorophosphate,

e) $\eta^{5}$-2,4-cyclopentadien-1-yl) [(1,2,3,4,5,6- $)$-(1-methylethyl)benzene]-iron hexafluorophosphate

The efficiency of triethanolamine as a protecting agent of cationically curable systems against premature polymerization was tested by measuring of viscosity changes at room and elevated temperatures. Increase of viscosity reflects changes in the distribution of molecular weights in the system or structural changes caused by premature polymerization. The stability of prepared samples was measured during twenty three weeks. Part of samples was exposed to elevated temperature $\left(60^{\circ} \mathrm{C}\right)$ few times $(1 ; 1.5 ; 5$; 5 and 11 hours). Flow curves of the samples were measured at $22^{\circ} \mathrm{C}$ in the range to $1000 \mathrm{~s}^{-1}$ shear rate using a Haake Rotovisco 1 rotary viscometer equipped with a cone sensor C20/1. The viscosity was determined from the flow curve as a mean value of steady values of the apparent viscosities (Figure 2).

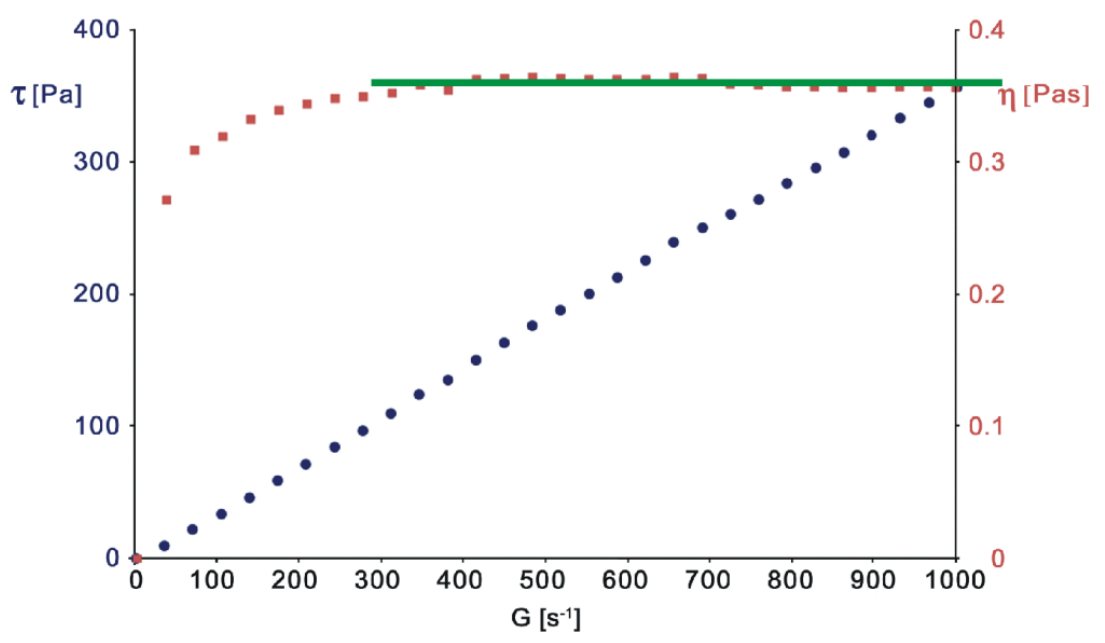

Figure 2: Example of the flow curve evaluation

The influence of additive on photoinitiated polymerization was tested by evaluation of conversion degree of the monomer after UV exposition. The infrared spectra were recorded by means of FTIR spectrometer Avatar 320 (Nicolet Instrument Corp., USA). The samples were irradiated by a medium pressure mercury lamp (UV tunnel Miniterm 220, Aeroterm, Czech Republic). The average UV dose per sample was $750 \mathrm{~mJ} / \mathrm{cm}^{2}$. The degree of conversion at time it was evaluated according to the formula:

$\alpha_{t}=\frac{\frac{A_{0}}{R_{0}}-\frac{A_{t}}{R_{t}}}{\frac{A_{0}}{R_{0}}} \cdot 100$ 
where $A_{0}$ and Ro are areas of the epoxide tripleband (approximately $800 \mathrm{~cm}^{-1}$ ) and the reference carbonyl $\left(1730 \mathrm{~cm}^{-1}\right)$ absorption bands before UV exposition, resp., $A_{t}, R_{t}$ are areas of these absorption bands after UV exposition and the defined time lag (see Figure 3).
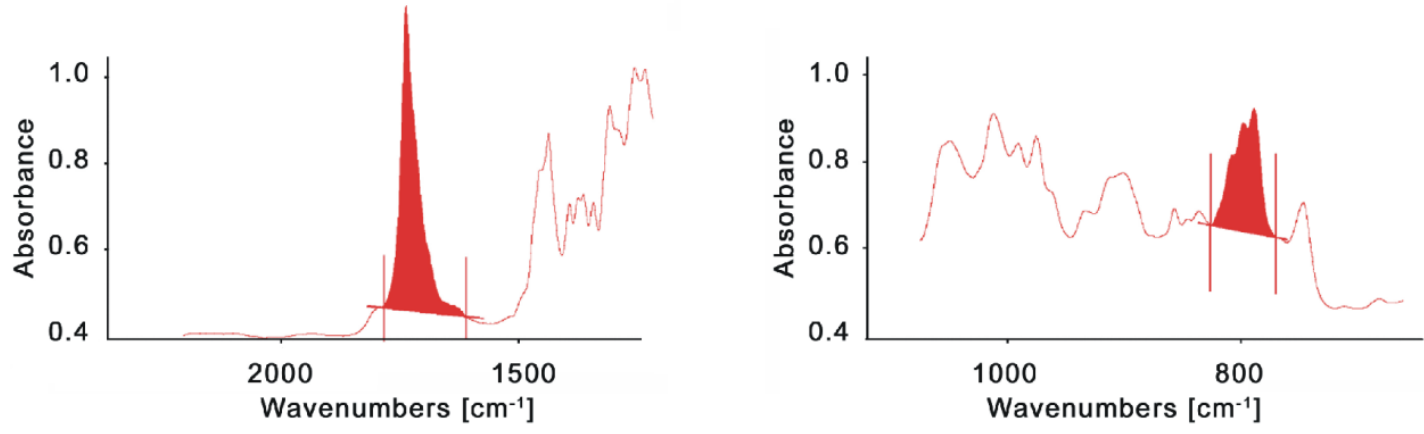

Figure 3: Example of the areas of absorption bands evaluation

\section{RESULTS}

The test results are summarized in Table 1 . Samples 250 contained 3 weight $\%$ of the iodonium salt as a photoinitiator, samples 270 contained 3 weight $\%$ of the sulfonium salt as a photoinitiator and samples 251 contained 3 weight \% of the organometallic salt as a photoinitiator. Samples A contained 1 weight \% of the triethanolamine as an inhibitor of premature polymerization, samples $\mathrm{C}$ were stored in the refrigerator throughout the test period $\left(4^{\circ} \mathrm{C}\right)$ and samples $\mathrm{H}$ were heated to $60^{\circ} \mathrm{C}$.

Table 1: Results

\begin{tabular}{lcccccccc}
\hline Heating [hours] & 0 & 1 & 2.5 & 7.5 & 12.5 & 23.5 & \multicolumn{2}{c}{ (only H samples were heated*) } \\
\hline $\begin{array}{l}\text { Storage [weeks] } \\
\text { Sample }\end{array}$ & 1 & 4 & $\begin{array}{c}11 \\
\text { Upper limit viscosity [mPas] }\end{array}$ & 23 & $\begin{array}{c}\text { Premature } \\
\text { polymerization }\end{array}$ & $\begin{array}{c}\text { Conversion } \\
\text { [\%] }\end{array}$ \\
\hline 250 & 0.63 & 0.65 & 0.66 & 0.67 & 0.78 & 0.88 & yes & 98.7 \\
\hline $250-\mathrm{H}$ & 0.63 & 0.61 & 0.67 & 0.79 & 1.06 & 1.46 & yes & 95.8 \\
\hline $250-\mathrm{C}$ & 0.63 & & & & & 0.60 & no & 95.9 \\
\hline $250 \mathrm{~A}$ & 0.44 & 0.44 & 0.44 & 0.41 & 0.44 & 0.42 & no & 56.7 \\
\hline $250 \mathrm{~A}-\mathrm{H}$ & 0.44 & 0.42 & 0.42 & 0.42 & 0.45 & 0.44 & no & 67.5 \\
\hline $250 \mathrm{~A}-\mathrm{C}$ & 0.44 & & & & & 0.44 & no & 66.1 \\
\hline 270 & 0.57 & 0.57 & 0.54 & 0.57 & 0.57 & 0.53 & no & 88.1 \\
\hline $270-\mathrm{H}$ & 0.57 & 0.58 & 0.54 & 0.58 & 0.58 & 0.58 & no & 87.8 \\
\hline $270-\mathrm{C}$ & 0.57 & & & & & 0.57 & no & 92.0 \\
\hline $270 \mathrm{~A}$ & 0.54 & 0.55 & 0.53 & 0.53 & 0.55 & 0.51 & no & 87.3 \\
\hline $270 \mathrm{~A}-\mathrm{H}$ & 0.54 & 0.52 & 0.52 & 0.52 & 0.56 & 0.55 & no & 87.9 \\
\hline $270 \mathrm{~A}-\mathrm{C}$ & 0.54 & & & & & 0.54 & no & 85.7 \\
\hline 261 & 0.51 & 0.52 & 0.52 & 0.52 & 0.51 & 0.51 & no & 91.7 \\
\hline $261-\mathrm{H}$ & 0.51 & 0.51 & 0.49 & 0.52 & 0.52 & 0.53 & no & 92.5 \\
\hline $261-\mathrm{C}$ & 0.51 & & & & & 0.52 & no & 97.3 \\
\hline $261 \mathrm{~A}$ & 0.46 & 0.47 & 0.46 & 0.45 & 0.48 & 0.48 & no & 89.5 \\
\hline $261 \mathrm{~A}-\mathrm{H}$ & 0.46 & 0.49 & 0.49 & 0.52 & 0.54 & 0.55 & no & 88.6 \\
\hline $261 \mathrm{~A}-\mathrm{C}$ & 0.46 & & & & & 0.51 & no & 90.8 \\
\hline
\end{tabular}

*H samples were heated $\left(60^{\circ} \mathrm{C}\right]$; C samples were stored in the refrigerator $\left(4^{\circ} \mathrm{C}\right)$; A sample contained the amine 


\section{CONCLUSIONS}

Premature polymerization occurs in mixtures containing the iodonium salt as photoinitiator mainly at elevated temperature, but also at room temperature (slightly). Addition of the triethanolamine effectively suppressed the premature polymerization of samples containing iodonium salt, but the presence of triethanolamine significantly reduces final degree of conversion (with iodonium salt as photoinitiator).

Samples containing the iron-arene and the sulphonium photoinitiators did not show premature polymerization. The presence of triethanolamine in this case only slightly reduces the final degree of conversion. No sample stored in refrigerator showed premature polymerization.

\section{REFERENCES}

[1] Crivello, J. V., Dietliker, K., edited by: Bradley, G.: "Photoinitiators for Free Radical, Cationic \& Anionic Photopolymerization", $2^{\text {nd }}$ ed, (John Wiley \& Sons, Chichester, 1998).

[2] Kondo, A.: EP 1852477 A1, "Ink set for inkjet, and method for forming image and inkjet recording device using the same", Konica Minolta Medical \& Graphic Inc., 2007.

[3] Rinker, K.: US 2010/0304284 A1, "Thermally stable cationic photocurable compositions", BASF Corporation, 2010.

[4] Takabayashi, T., Sekiguchi, R.: US 2006/0050121 A1, “Activated light curable inkjet ink and image formation method", Konica Minolta Medical \& Graphic Inc., 2006.

[5] Toagosei America Inc., Aron Oxetane Technical Information, Aronalpha, URL: http://instantadhesives.aronalpha.net/Asset/OXETANE TDS.pdf (last request: 2018-07-21).

[6] Yagci, Y., Reetz, I.: "Externally stimulated initiator systems for cationic polymerization", Progress in Polymer Science, 23 (8), 1485-1538, 1998. doi: 10.1016/S0079-6700(98)00010-0

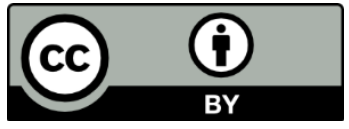

(C) 2018 Authors. Published by the University of Novi Sad, Faculty of Technical Sciences, Department of Graphic Engineering and Design. This article is an open access article distributed under the terms and conditions of the Creative Commons Attribution license 3.0 Serbia (http://creativecommons.org/licenses/by/3.0/rs/). 